\title{
Quality of life as a prognostic marker in pulmonary arterial hypertension
}

\author{
Caio JCS Fernandes ${ }^{1}$, Barbara CS Martins ${ }^{1}$, Carlos VP Jardim', Rozana M Ciconelli', Luciana K Morinaga', \\ Ana Paula Breda', Susana Hoette ${ }^{1}$ and Rogério Souza ${ }^{1 *}$
}

\begin{abstract}
Background: Improvement in quality of life together with better survival are the ultimate goals in the treatment of pulmonary arterial hypertension (PAH) patients. The objective of this study was to evaluate the health-related quality of life (HRQL) of pulmonary arterial hypertension (PAH) patients with the SF-36 generic questionnaire and to identify the prognostic implication of this assessment.

Methods: Fifty-four consecutive newly diagnosed PAH patients (WHO classification group I) in a single PAH reference center were included. Patients were evaluated at baseline for clinical and hemodynamic parameters, and they subsequently received first-line therapy with either an endothelin receptor antagonist or a phosphodiesterase- 5 inhibitor. After 16 weeks of specific PAH therapy, all patients were re-evaluated using a 6MWT and a SF 36 questionnaire, and then they were followed up for at least 36 months.

Results: After treatment, the patients demonstrated an improved 6MWT (414 $\pm 124 \mathrm{~m}$ vs. $440 \pm 113 \mathrm{~m}, \mathrm{p}=0.001)$. Specific PAH therapy also improved the HRQL scores.

Patients with a baseline Physical Component Score (PCS) higher than 32 had a better survival rate than those who had a score under $32(p=0.04)$. Similarly, patients with a PCS of at least a 38 after the 16 week therapy period had a better survival rate when compared with those who did not achieve this value $(p=0.016)$. Unlike the absolute PCS values, the post-treatment PCS variability was unable to predict better survival rates $(p=0.58)$.

Conclusions: Our findings suggest that HRQL is associated with prognosis in PAH. Furthermore, achieving pre-determined PCS scores might represent a specific goal to be reached in treatment-to-target strategies.
\end{abstract}

Keywords: Quality of life, Pulmonary arterial hypertension, Survival, Prognosis, Treatment

\section{Introduction}

Pulmonary arterial hypertension (PAH) is a chronic disease caused by elevated pressure in the lung vasculature, eventually leading to the right ventricle failure and death due to circulatory collapse [1]. PAH is a rare condition with an annual incidence of 1.1 to 7.6 cases per million and a prevalence of 15 to 26 cases per million [2]. Consequently, the development of clinical trials with useful endpoints is challenging because mortality, as the primary endpoint, is usually not feasible. Therefore, alternative methods for evaluating the clinical responses to

\footnotetext{
* Correspondence: souza.rogerio@me.com

${ }^{1}$ Pulmonary Department, Heart Institute - University of Sao Paulo Medical School, Medical School. Av. Dr. Eneas de Carvalho Aguiar, 44, 05403-000 Sao Paulo, Brazil

Full list of author information is available at the end of the article
}

specific PAH therapies were widely used in the design of randomized, controlled trials and in clinical practice [3].

Studies that addressed targeted PAH therapies, such as prostanoids [4], endothelin receptors antagonists (ERA) [5], and phosphodiesterase-5 inhibitors (PDE5i) [6], have demonstrated that several parameters, including the New York Heart Association functional class assessment, the six-minute walk test $(6 \mathrm{MWT})$, serum biomarkers (BNP and NT-ProBNP) [7-9] and invasive hemodynamic (Cardiac Index, Mean Pulmonary Artery Pressure and Right Atrium Pressure) measurements, closely associate with disease severity and are directly improved by medical treatments suggesting a potentially positive influence of these therapies on PAH patients' mortality [10].

Nevertheless, the main objective of specific therapies for $\mathrm{PAH}$ patients was to improve not only the quantity 
of life, or survival, but also the quality of life. PAH patients are well known to have a severely impaired health-related quality of life (HRQL) [11]. Reports of evaluation tools that specifically address the impaired HRQL induced by PAH are still limited in the literature $[12,13]$ and are not routinely employed in general practice in $\mathrm{PAH}$ patients. The development of PAH treatment strategies that could simultaneously evaluate both the quantity and quality of life would be potentially useful in the clinical management of this disease.

Quality of life can be evaluated in several chronic diseases using specific and validated inquiries such as the Short-Form 36 Health Survey (SF-36) [14]. This highly reproducible, well-known, non-invasive and frequently used survey, for such evaluations, is widely available in several different languages [15]. Although specific PAH therapies have already been demonstrated to improve HRQL [16-19], the association of this improvement and survival has not been properly addressed.

The aim of this study was to evaluate the impact of targeted PAH therapies on the HRQL using the SF-36 and addressing HRQL association to survival.

\section{Methods}

\section{Patient population}

Newly diagnosed PAH patients (group I of the Dana Point Classification system) [20] followed in a large PAH reference center (Heart Institute) in São Paulo, Brazil, were included in this study. The protocol was approved by the Institutional Review Board.

The baseline patient evaluations included obtaining information on demographics and medical histories and included the New York Heart Association (NYHA) functional class assessments, physical examinations and routine laboratory tests. Data from 6MWT assessments [21], quality of life questionnaires [19] and right heart catheterizations using standard techniques were also obtained [22].

The PAH patients' quality of life was assessed using the SF 36 questionnaire, which consists of 36 questions covering eight domains. Four domains are projected to reflect the impact of the disease on the physical component of the patients life (Physical Component Score PCS), and the four remaining domains are projected to reflect the impairment caused by the disease on mental status (Mental Component Score - MCS). The scores were converted to a 100-points score scale where higher scores indicated a better QOL. The SF-36 questionnaire was given by a person trained to use the QOL assessment tool [15] and was chosen because it had been validated for use in the native language of the patients who comprised the study [23].

Patients with PAH are defined as having a mean pulmonary artery pressure $(\mathrm{mPAP})>25 \mathrm{mmHg}$ with a normal pulmonary artery occlusion pressure (PAOP $<15$ $\mathrm{mmHg}$ ) [20]. Patients were classified as having idiopathic pulmonary arterial hypertension (IPAH) when $\mathrm{PAH}$ was diagnosed in the absence of chronic thromboembolic pulmonary hypertension and was not associated with significant left heart or lung disease or with other known conditions, including HIV infection, portal hypertension, congenital systemic-pulmonary shunts, connective tissue diseases and exposure to appetite suppressants. Patients were classified as having schistosomiasisassociated PAH (Sch-PAH) when the presence of PAH was associated with liver ultrasonographic observations that were highly suggestive of mansonic schistosomiasis (left lobe enlargement and/or periportal fibrosis). Additionally, the patients must demonstrate at least one of the following features: 1) the endemic regional exposure to schistosomiasis, 2) previous treatment for schistosomiasis and 3) the presence of Schistosoma mansoni eggs in the stool following examinations or rectal biopsies $[24,25]$.

\section{Treatments}

In the absence of any contraindication (e.g., high risk of gastrointestinal bleeding or presence of esophageal varices) the patients received oral anticoagulation; diuretics and oxygen were prescribed as needed.

Patients received a PAH first-line therapy of either an ERA or a PDE5i. The choice between the agents was based on the drug availability at our facility. After 16 weeks of specific PAH therapy, all patients were reevaluated by means of the 6MWT and the SF $36 \mathrm{HRQL}$ questionnaire. Patients were then followed up for up to 36 months for survival analysis.

\section{Statistical analysis}

Analysis was performed using the SPSS 15 statistical package (SPSS, Inc., Chicago, IL). All continuous variables are expressed as median $\pm \mathrm{SD}$, whereas the categorical data are presented as proportions. The Cronbach's $\alpha$ coefficient was calculated for all SF 36 scores to verify the questionnaire reproducibility and reliability, and values higher than 0.7 were considered satisfactory.

To compare the baseline and post-treatment characteristics, a paired t-test was used. For survival analysis, the first hemodynamic evaluation was considered to be the date of diagnosis. All-cause mortality was used because of the lack of information about the specific cause of death in several cases. No patients were lost to follow-up during the study period. The patient survival was estimated using the Kaplan-Meier method, and the log-rank test was applied to compare these curves. A p-value of less than 0.05 was considered as statistically significant. 


\section{Results}

The study population consisted of 54 PAH patients. The baseline clinical, functional and hemodynamic data are shown in Table 1 and are compatible to previously published series for PAH patients.

After the 16-week treatment period using an ERA (in $85 \%$ of all cases) or a PDE5i (in the remaining 15\%), patients demonstrated a significantly improved 6MWT $(414 \pm 124 \mathrm{~m}$ vs. $440 \pm 113 \mathrm{~m}, \mathrm{p}=0.001)$ as well as in functional class $(\mathrm{p}=0.02)$. Specific PAH therapy also improved the HRQL scores as evaluated by the SF 36 for all the domains except for bodily pain (Figure 1). The Cronbach's $\alpha$ coefficient was found to be 0.852 and considered adequate. Interestingly, baseline PCS correlated with 6MWD $(\mathrm{r}=0.493, \mathrm{p}<0.01)$ and also with functional class $(\mathrm{r}=-0.576, \mathrm{p}<0.01)$.

Furthermore, the HRQL scores were able to discriminate between patients with a better survival both in the baseline and in the post-treatment periods. Patients with a baseline PCS higher than the median value (32) had a significantly improved survival $(\mathrm{p}=0.04$, Figure 2$)$. A similar pattern was found in the post-treatment evaluation; patients who reached more than the median post-treatment PCS value (38) had a better survival rate when compared to those who did not reach this

Table 1 Baseline clinical and hemodynamic data $(n=54)$

\begin{tabular}{ll}
\hline Age (years) & $\mathbf{4 4 \pm 1 2}$ \\
\hline Sex (f/m) & $45 / 9$ \\
Etiology n (\%) & \\
Idiopathic & $37(68)$ \\
Associated to & \\
Schistosomiasis & $7(13)$ \\
CTD & $8(15)$ \\
CHD & $2(4)$ \\
NYHA functional class n (\%) & \\
॥I & $14(26)$ \\
III & $28(52)$ \\
IV & $12(22)$ \\
6MWT (m) & $418 \pm 121$ \\
mPAP (mmHg) & $64 \pm 17$ \\
PAOP (mmHg) & $10 \pm 2$ \\
Cardiac output (L/min) & $4 \pm 1$ \\
PVR (WU) & $15 \pm 8$ \\
Therapy n (\%) & \\
ERA & \\
PDE-5 inhibitors & $46(85)$ \\
\hline
\end{tabular}

CTD Connective tissue disease, CHD Congenital heart disease, NYHA New York Heart Association, $6 M W T$ Length in non-encouraged six-minute-walk test, RAP Right Atrial Pressure, MPAP Mean Pulmonary Artery Pressure, PAOP Pulmonary Artery Occlusion Pressure, PVR Pulmonary Vascular Resistance, ERA Endothelin Receptor Antagonists, PDE-5 Phosphodiesterase-5 inhibitor. threshold ( $p=0.016$, Figure 3$)$. Notably, the absolute change in PCS after treatment was not predictor of survival in this study $(\mathrm{p}=0.58$, Figure 4$)$.

\section{Discussion}

This study demonstrated the association of HRQL assessment, more specifically, the use of the SF 36 questionnaire, with prognosis in PAH. The baseline HRQL measurements can distinguish a high-risk subgroup of PAH patients with a poor survival outlook. Furthermore, HRQL might also represent a viable treatment goal because reaching a specific post-treatment threshold on the PCS was associated with better survival.

The aim of specific PAH therapy is to improve patient survival. However, despite all the recent advances in diagnostic and therapeutic modalities for $\mathrm{PAH}$, the mortality rate remains high, with a 5 -year survival of $57 \%$ [26]. Despite the need for improved treatment strategies, these data also reinforce the significance of improving the HRQL for such a relentless and progressive disease. Our study attempts to concatenate both survival and quality of life evaluations as a result of specific drug therapy. While attempting to improve the HRQL and establishing harder endpoints for clinical therapy, it is possible that better survival rates might also be achieved.

Previous studies have already demonstrated that the HRQL of PAH patients is severely reduced when compared to healthy individuals [11]. PAH patients present with reduced physical mobility, significant dyspnea and increased difficulties in social interactions. Some trials involving PAH patients, when evaluating the response to different therapies, used HRQL questionnaires as secondary endpoints but reached variable results. One study showed that the HRQL improved modestly after bosentan therapy and this improvement was stable for 3 months [16]. The same response pattern was also described with another ERA, sitaxsentan [27]. However, the HRQL remained unchanged in other clinical trials using therapeutic drugs known to be effective for PAH patients such as treprostinil [4] and ambrisentan [28]. Nevertheless, recent systematic review on the effect of targeted therapies in HRQL of PAH patients demonstrated that HRQL consistently improved after specific intervention, even considering the heterogeneity of the instruments used for quality of life evaluation among the different studies [29]. In our study, except for bodily pain, all domains significantly improved after treatment with specific PAH therapies, resulting also in a significant improvement in the physical component score as in the mental component score.

Recently, Roman et al. described the HRQL of PAH and chronic thromboembolic pulmonary hypertension (CTEPH) Spanish cohorts and described similar baseline results to those in our study [30]. In the Roman et al. study, both the SF-36 and EuroQol 5D questionnaires 


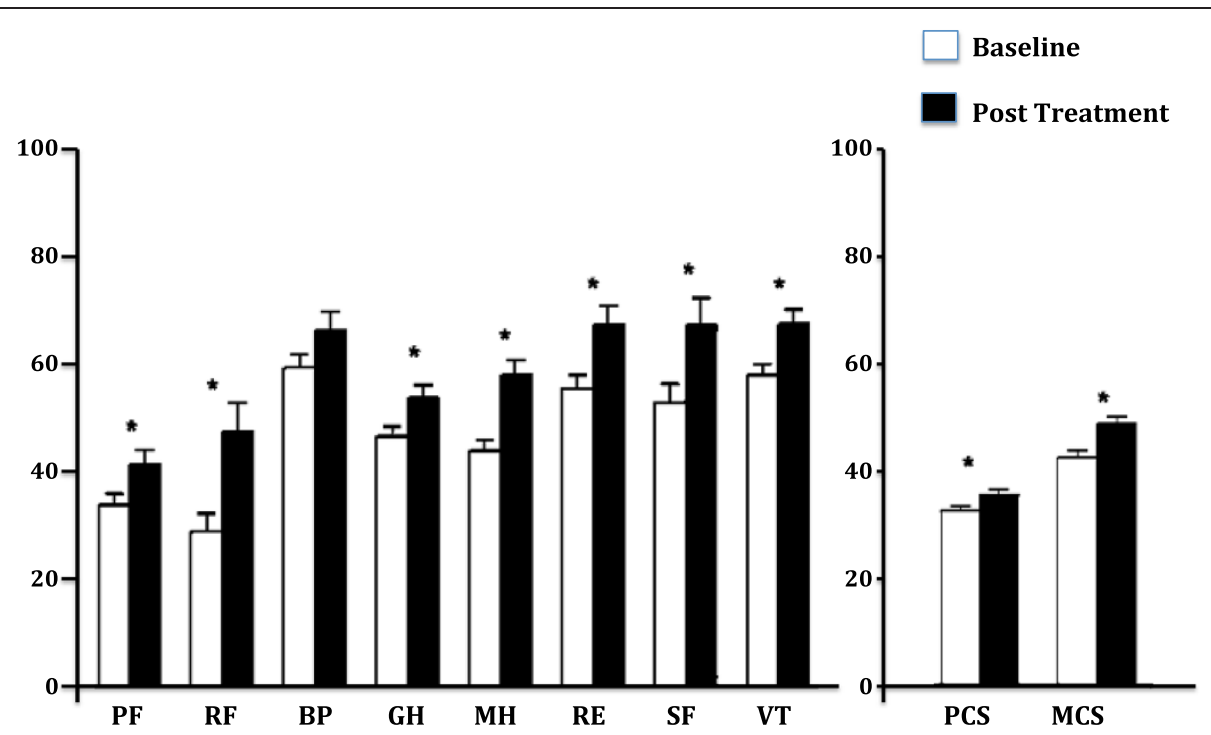

Figure 1 SF-36 score domains variations after specific PAH therapy for 16 weeks (* $\mathbf{p}<0.05$ ). PF - Physical Function, RF - Role Physical, BP - Bodily Pain, GH - General Health, MH - Mental Health, RE - Role Emotional, SF - Social Function, VT - Vitality, PCS - Physical Component Score, MCS - Mental Component Score.

were able to identify the patients with a worse prognosis. Nevertheless, our study is the first to demonstrate that the clinical response to specific PAH therapy could be effectively measured using a SF-36 questionnaire. In our study, the baseline physical score component and the PCS after 16 weeks of specific PAH treatment was associated with patient survival. In a pattern similar to one previously described for the 6MWT [31], the absolute variation of PCS after treatment was not associated with survival suggesting that achieving a specific PCS threshold is more important than improving the PCS itself to determine a better prognosis. This is the first time that a specific goal associated to HRQL is described in addition to others previously defined in the literature [32].

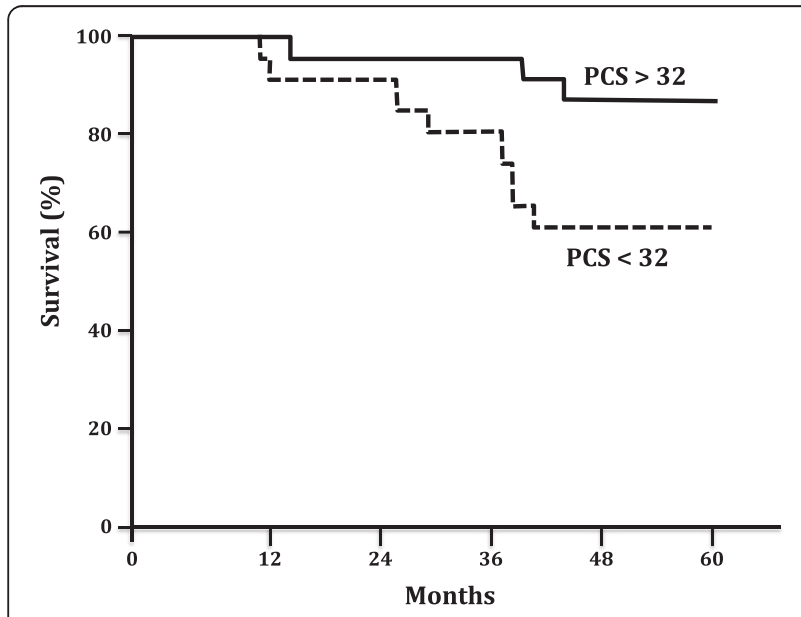

Figure 2 Kaplan Meier survival rates according baseline SF-36 Physical Component Score (PCS). Log rank test, $\mathrm{p}=0.04$.
For 6MWT, it has been previously suggested that improvements of $33 \mathrm{~m}$ would represent the minimal important difference (MID) to reflect improvements in the quality of life of PAH patients [17]. A more recent analysis of the raw data from ten different trials tried to establish the relationship between the changes in 6MWD and the probability of clinical deterioration to occur [33]. In this study, Gabler et al. demonstrated that on average 6MWD improved by $22.4 \mathrm{~m}$ with active treatment; however, this improvement accounted only for a small proportion of the treatment effect, suggesting the change in 6MWT would not represent a valid surrogate in $\mathrm{PAH}$, confirming the previous findings from Sitbon et al.

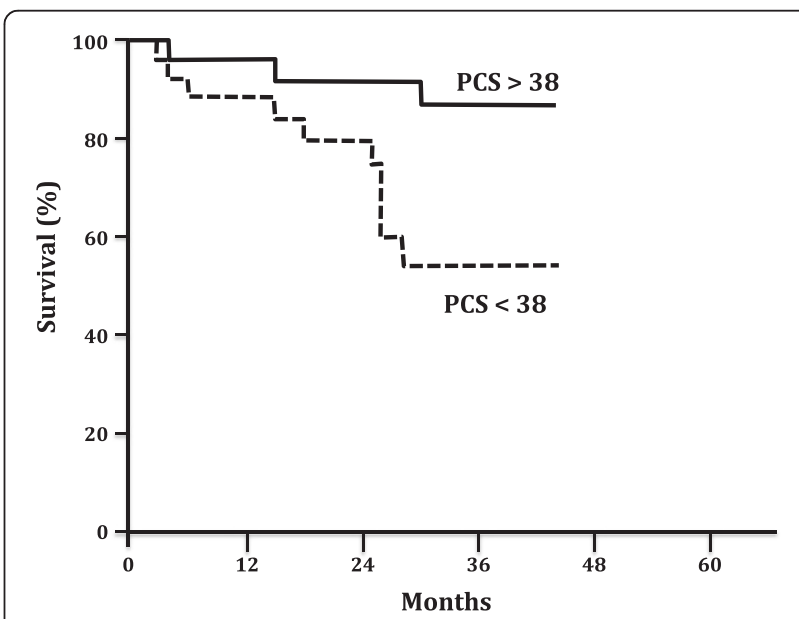

Figure 3 Kaplan Meier survival rates according SF-36 Physical Component Score (PCS) after 16 weeks of specific PAH therapy. Log rank test, $\mathrm{p}=0.016$. 


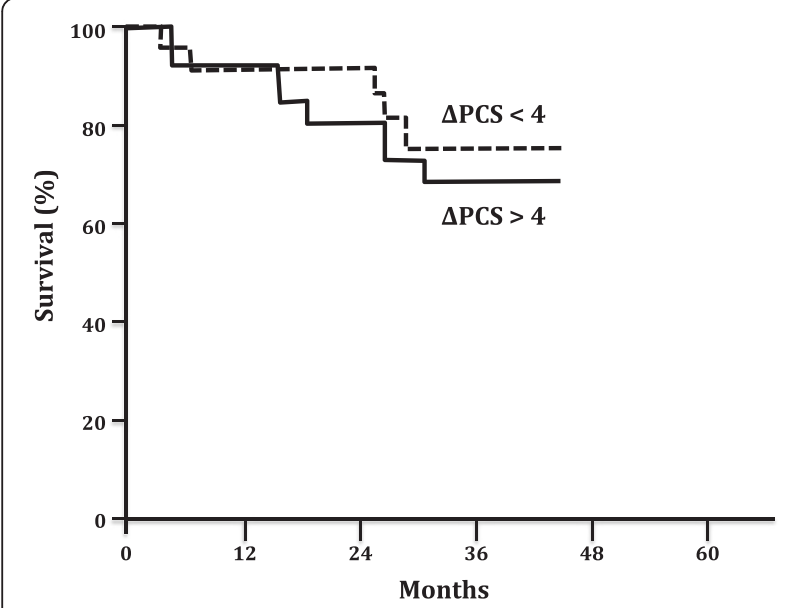

Figure 4 Kaplan Meier survival rates according variation of SF-36 Physical Component Score (PCS) after 16 weeks of specific PAH therapy. Log rank test, $p=0.58$.

[31]. These studies, in line with our results, suggested that a minimum functional status should be reached in order to reflect better prognosis.

A MID in SF-36 scores has been suggested for PAH. Gilbert et al. mathematically determined the MID, throughout distribution-based models, suggesting MID of 13 to 25, depending on the domain of the SF-36 [34]. No analysis on the physical or mental component scores were reported. The same study suggested a MID of $41 \mathrm{~m}$ for the 6MWT. However, the analysis was based solely on the distribution of the results, since the authors had no surrogate marker to use as an anchor to determine the relevance of the MID, thus preventing the extrapolation of the results; differently, our study used survival as a hard endpoint for the analysis of the minimum threshold in HRQL, more specifically in PCS, that could reflect better long-term survival in PAH.

In 2006 McKenna et al developed a HRQL scale specifically for the PAH population using the Cambridge Pulmonary Hypertension Outcome Review (CAMPHOR) [13]. The CAMPHOR questionnaire comprises overall symptoms (comprising Energy, Breathlessness and Mood subscales), functionality and HRQL, and demonstrated good values for the Cronbach's $\alpha$ coefficient, and reproducibility. Recently, several studies used the CAMPHOR scale in several cohorts across the world and validated the questionnaire in German [35], French-Canadian [36] and Swedish [37] languages. The CAMPHOR questionnaire was also applied to different English-speaking PAH patient populations such as American [38], Canadian [36], Australian and New Zealander [39] with good results. However, the predictive value of CAMPHOR appears to be restricted to baseline evaluations. Recently, McCabe et al demonstrated that repeated CAMPHOR assessments over time did not add any predictive value for clinical deterioration to that obtained at diagnosis in an IPAH population followed for 8 years [40]. These data limit the prospective utility of CAMPHOR assessments for clinical follow-up.

This study has limitations that need to be acknowledged. First, it was a single center study in a country with a peculiar distribution of PAH etiologies where schistosomiasis-associated pulmonary arterial hypertension holds high epidemiologic relevance [41-43]. Although our center is the largest reference center in the country, the potential selection bias associated with this limitation should be taken into consideration when extrapolating our results. Furthermore, we decided not to use a health-related quality of life questionnaire specific for $\mathrm{PAH}$, but a general one, projected to evaluate chronic diseases. Nevertheless, the SF-36 is the best-known and studied HRQL questionnaire, worldwide; additionally, it is rapid, easy and reliable.

Despite these limitations, our results support the association of PAH prognosis with general HRQL evaluation with the SF-36 questionnaire, at baseline and after specific PAH therapies. Moreover, achieving pre-determined PCS scores might represent a specific goal to be reached in treatment-to-target strategies, as currently is recommended for PAH.

\section{Competing interests}

The authors declare no conflict of interest with the content of this manuscript.

\section{Authors' contribution}

$B M, C J, R S$ designed the study. CF, BM, CJ, LM, AB, SH collected the data. CF, $B M, R C, R S$ analyzed the results. CF, RC, RS wrote the first version of the manuscript. All authors read and approved the final manuscript.

\section{Author details}

${ }^{1}$ Pulmonary Department, Heart Institute - University of Sao Paulo Medical School, Medical School. Av. Dr. Eneas de Carvalho Aguiar, 44, 05403-000 Sao Paulo, Brazil. ${ }^{2}$ Rheumatology Department, Federal University of Sao Paulo, Sao Paulo, Brazil.

Received: 25 March 2014 Accepted: 8 August 2014

Published online: 30 August 2014

\section{References}

1. Souza R, Jardim C, Humbert M: Idiopathic pulmonary arterial hypertension. Semin Respir Crit Care Med 2013, 34:560-567.

2. McGoon MD, Benza RL, Escribano-Subias P, Jiang X, Miller DP, Peacock AJ, Pepke-Zaba J, Pulido T, Rich S, Rosenkranz S, Suissa S, Humbert M: Pulmonary arterial hypertension: epidemiology and registries. J Am Coll Cardiol 2013, 62:D51-D59.

3. Hoette $S$, Jardim C, Souza R: Diagnosis and treatment of pulmonary hypertension: an update. J Bras Pneumol 2010, 36:795-811.

4. Simonneau G, Barst RJ, Galie N, Naeije R, Rich S, Bourge RC, Keogh A, Oudiz R, Frost A, Blackburn SD, Crow JW, Rubin LJ, Treprostinil Study Group: Continuous subcutaneous infusion of treprostinil, a prostacyclin analogue, in patients with pulmonary arterial hypertension: a double-blind, randomized, placebo-controlled trial. Am J Respir Crit Care Med 2002, 165:800-804.

5. Rubin LJ, Badesch DB, Barst RJ, Galie N, Black CM, Keogh A, Pulido T, Frost A, Roux S, Leconte I, Landzberg M, Simonneau G: Bosentan therapy for pulmonary arterial hypertension. N Engl J Med 2002, 346:896-903. 
6. Galie N, Ghofrani HA, Torbicki A, Barst RJ, Rubin LJ, Badesch D, Fleming T, Parpia T, Burgess G, Branzi A, Grimminger F, Kurzyna M, Simonneau G: Sildenafil citrate therapy for pulmonary arterial hypertension. $N$ Engl J Med 2005, 353:2148-2157.

7. Fijalkowska A, Kurzyna M, Torbicki A, Szewczyk G, Florczyk M, Pruszczyk P, Szturmowicz M: Serum N-terminal brain natriuretic peptide as a prognostic parameter in patients with pulmonary hypertension. Chest 2006, 129:1313-1321.

8. Souza R, Jardim C, Carvalho C, Rubenfeld G: The role of NT-proBNP as a prognostic marker in pulmonary hypertension. Chest 2006, 130:1627. author reply 1627-8.

9. Souza R, Jardim C, Julio Cesar Fernandes C, Silveira Lapa M, Rabelo R, Humbert M: NT-proBNP as a tool to stratify disease severity in pulmonary arterial hypertension. Respir Med 2007, 101:69-75.

10. Galie N, Manes A, Negro L, Palazzini M, Bacchi-Reggiani ML, Branzi A: A meta-analysis of randomized controlled trials in pulmonary arterial hypertension. Eur Heart J 2009, 30:394-403.

11. Shafazand S, Goldstein MK, Doyle RL, Hlatky MA, Gould MK: Health-related quality of life in patients with pulmonary arterial hypertension. Chest 2004, 126:1452-1459.

12. Bonner N, Abetz L, Meunier J, Sikirica M, Mathai SC: Development and validation of the living with pulmonary hypertension questionnaire in pulmonary arterial hypertension patients. Health Qual Life Outcomes 2013, 11:161.

13. McKenna SP, Doughty N, Meads DM, Doward LC, Pepke-Zaba J: The Cambridge Pulmonary Hypertension Outcome Review (CAMPHOR): a measure of health-related quality of life and quality of life for patients with pulmonary hypertension. Qual Life Res 2006, 15:103-115.

14. McHorney CA, Ware JE Jr, Lu JF, Sherbourne CD, The MOS: 36-item Short-Form Health Survey (SF-36): III: tests of data quality, scaling assumptions, and reliability across diverse patient groups. Med Care 1994, 32:40-66.

15. Brazier JE, Harper R, Jones NM, O'Cathain A, Thomas KJ, Usherwood T, Westlake L: Validating the SF-36 health survey questionnaire: new outcome measure for primary care. BMJ 1992, 305:160-164

16. Keogh AM, McNeil KD, Wlodarczyk J, Gabbay E, Williams TJ: Quality of life in pulmonary arterial hypertension: improvement and maintenance with bosentan. J Heart Lung Transplant 2007, 26:181-187.

17. Pepke-Zaba J, Beardsworth A, Chan M, Angalakuditi M: Tadalafil therapy and health-related quality of life in pulmonary arterial hypertension. Curr Med Res Opin 2009, 25:2479-2485.

18. Simonneau G, Rubin LJ, Galie N, Barst RJ, Fleming TR, Frost AE, Engel PJ, Kramer MR, Burgess G, Collings L, Cossons N, Sitbon O, Badesch DB, PACES Study Group: Addition of sildenafil to long-term intravenous epoprostenol therapy in patients with pulmonary arterial hypertension: a randomized trial. Ann Intern Med 2008, 149:521-530

19. Souza R, Jardim C, Martins B, Cortopassi F, Yaksic M, Rabelo R, Bogossian H: Effect of bosentan treatment on surrogate markers in pulmonary arterial hypertension. Curr Med Res Opin 2005, 21:907-911.

20. Simonneau G, Gatzoulis MA, Adatia I, Celermajer D, Denton C, Ghofrani A, Gomez Sanchez MA, Krishna Kumar R, Landzberg M, Machado RF, Olschewski H, Robbins IM, Souza R: Updated clinical classification of pulmonary hypertension. J Am Coll Cardiol 2013, 62:D34-D41.

21. ATS statement: guidelines for the six-minute walk test. Am J Respir Crit Care Med 2002, 166:111-117.

22. Costa EL, Jardim C, Bogossian HB, Amato MB, Carvalho CR, Souza R: Acute vasodilator test in pulmonary arterial hypertension: evaluation of two response criteria. Vascul Pharmacol 2005, 43:143-147.

23. Ciconelli R, Ferraz MB, Santos W, Quaresma M: Tradução para a Língua Portuguesa e validação do questionário genérico da avaliação de qualidade de vida SF-36 (Brasil SF-36). Rev Bras Reumatol 1999, 39:8.

24. Fernandes CJ, Jardim CV, Hovnanian A, Hoette S, Morinaga LK, Souza R: Schistosomiasis and pulmonary hypertension. Expert Rev Respir Med 2011, 5:675-681.

25. Hovnanian A, Hoette S, Fernandes CJ, Jardim C, Souza R: Schistosomiasis associated pulmonary hypertension. Int J Clin Pract Suppl 2010, 25-28.

26. Benza RL, Miller DP, Barst RJ, Badesch DB, Frost AE, McGoon MD: An evaluation of long-term survival from time of diagnosis in pulmonary arterial hypertension from the REVEAL Registry. Chest 2012, 142:448-456.

27. Souza R, Martins BC, Jardim C, Cortopassi F, Fernandes CJ, Pulido T, Sandoval J: Effect of sitaxsentan treatment on quality of life in pulmonary arterial hypertension. Int J Clin Pract 2007, 61:153-156.
28. Galie N, Olschewski H, Oudiz RJ, Torres F, Frost A, Ghofrani HA, Badesch DB, McGoon MD, McLaughlin W, Roecker EB, Gerber MJ, Dufton C, Wiens BL, Rubin $L$ : Ambrisentan for the treatment of pulmonary arterial hypertension: results of the ambrisentan in pulmonary arterial hypertension, randomized, double-blind, placebo-controlled, multicenter, efficacy (ARIES) study 1 and 2. Circulation 2008, 117:3010-3019.

29. Rival G, Lacasse Y, Martin S, Bonnet S, Provencher S: Effect of pulmonary arterial hypertension specific therapies on health-related quality of life: a systematic review. Chest 2014.

30. Roman A, Barbera JA, Castillo MJ, Munoz R, Escribano P: Health-related quality of life in a national cohort of patients with pulmonary arterial hypertension or chronic thromboembolic pulmonary hypertension. Arch Bronconeumol 2013, 49:181-188.

31. Sitbon O, Humbert M, Nunes H, Parent F, Garcia G, Herve P, Rainisio M, Simonneau G: Long-term intravenous epoprostenol infusion in primary pulmonary hypertension: prognostic factors and survival. J Am Coll Cardiol 2002, 40:780-788.

32. Hoeper MM, Markevych I, Spiekerkoetter E, Welte T, Niedermeyer J: Goal-oriented treatment and combination therapy for pulmonary arterial hypertension. Eur Respir J 2005, 26:858-863.

33. Gabler NB, French B, Strom BL, Palevsky HI, Taichman DB, Kawut SM, Halpern SD: Validation of 6-minute walk distance as a surrogate end point in pulmonary arterial hypertension trials. Circulation 2012, 126:349-356.

34. Gilbert C, Brown MC, Cappelleri JC, Carlsson M, McKenna SP: Estimating a minimally important difference in pulmonary arterial hypertension following treatment with sildenafil. Chest 2009, 135:137-142.

35. Cima K, Twiss J, Speich R, McKenna SP, Grunig E, Kahler CM, Ehlken N, Treder U, Crawford SR, Huber LC, Ulrich S: The German adaptation of the Cambridge Pulmonary Hypertension Outcome Review (CAMPHOR). Health Qual Life Outcomes 2012, 10:110.

36. Coffin D, Duval K, Martel S, Granton J, Lefebvre MC, Meads DM, Twiss J, McKenna SP: Adaptation of the Cambridge Pulmonary Hypertension Outcome Review (CAMPHOR) into French-Canadian and English-Canadian. Can Respir J 2008, 15:77-83.

37. Selimovic N, Rundqvist B, Kjork E, Viriden J, Twiss J, McKenna SP: Adaptation and validation of the Cambridge pulmonary hypertension outcome review for Sweden. Scand J Public Health 2012, 40:777-783.

38. Gomberg-Maitland M, Thenappan T, Rizvi K, Chandra S, Meads DM, McKenna SP: United States validation of the Cambridge Pulmonary Hypertension Outcome Review (CAMPHOR). J Heart Lung Transplant 2008, 27:124-130.

39. Ganderton L, Jenkins S, McKenna SP, Gain K, Fowler R, Twiss J, Gabbay E: Validation of the Cambridge Pulmonary Hypertension Outcome Review (CAMPHOR) for the Australian and New Zealand population. Respirology 2011, 16:1235-1240.

40. McCabe C, Bennett M, Doughty N, MacKenzie Ross R, Sharples L, Pepke-Zaba J: Patient-reported outcomes assessed by the CAMPHOR questionnaire predict clinical deterioration in idiopathic pulmonary arterial hypertension and chronic thromboembolic pulmonary hypertension. Chest 2013, 144:522-530.

41. Dos Santos Fernandes CJ, Jardim CV, Hovnanian A, Hoette S, Dias BA, Souza S, Humbert M, Souza R: Survival in schistosomiasis-associated pulmonary arterial hypertension. J Am Coll Cardiol 2010, 56:715-720.

42. Fernandes CJ, Dias BA, Jardim CV, Hovnanian A, Hoette S, Morinaga LK, Souza S, Suesada M, Breda AP, Souza R: The role of target therapies in schistosomiasis-associated pulmonary arterial hypertension. Chest 2012, 141:923-928.

43. Lapa M, Dias B, Jardim C, Fernandes CJ, Dourado PM, Figueiredo M, Farias A, Tsutsui J, Terra-Filho M, Humbert M, Souza R: Cardiopulmonary manifestations of hepatosplenic schistosomiasis. Circulation 2009, 119:1518-1523.

doi:10.1186/s12955-014-0130-3

Cite this article as: Fernandes et al:: Quality of life as a prognostic marker in pulmonary arterial hypertension. Health and Quality of Life Outcomes 2014 12:130 